\title{
ASSESSMENT OF THE REPRODUCTIVE POTENTIAL OF WOMEN WITH HY-POTALAMIC SYNDROME
}

\section{M.G. Saliy, L.V. Tkachenko, R.V. Pavlov, E.G. Selina}

\section{Astrakhan State Medical University of the Ministry of Health of Russia, Astrakhan, Russia}

\begin{abstract}
The reproductive potential was evaluated in 87 women aged 19 to 32 years with hypothalamic syndrome in the Astrakhan region. Analysis of the survey results showed that $72,4 \%$ of the patients had menstrual and reproductive disorders. In the structure of menstrual dysfunction, hypomenstrual and hypermenstrual syndromes predominate, while among reproductive ones - primary infertility and miscarriage.
\end{abstract}

KEY W ORDS - hypothalamic syndrome, menstrual function, reproductive function, infertility, miscarriage, women.

\section{INTRODUCTION}

Protection of reproductive health is a state priority. Recently, there has been a steady increase in neuroendocrine pathology. According to various authors, hypothalamic syndrome (HS) occurs in $18-25 \%$ of women of reproductive age. Hypothalamic syndrome (HS) is a pathological symptom complex based on the primary lesion of the hypothalamus and associated central nervous system structures $[1,2,3]$. Various adverse factors during pregnancy can affect the structure of the hypothalamus and the formation of its connections. In most cases, HS without treatment transforms into neuro-endocrine syndrome, in which chronic anovulation causes infertility in $25-72 \%$ of women [5]. Chronic anovulation on the background of overweight and metabolic disorders can contribute to the development of hyperplastic processes and endometrial cancer $[4,6]$.

\section{MATERIALS AND METHODS OF THE RESEARCH}

The reproductive function was assessed in 87 women with hypothalamic syndrome aged 21 to 32 years (main group). The women of the main group were divided into 2 subgroups depending on body mass index (BMI). Subgroup 1 included patients with $\mathrm{BMI} \geq 30-45$ people, subgroup $2(\mathrm{BMI} \leq 30)-43$ patients. The control group consisted of 52 women without hypothalamic syndrome during the examination. The average age in the main group was $31.6 \pm 0,5$ years, in the control one $-30,9 \pm 1,2$ years. All subjects were comparable in history. All women were assessed by the levels of follicle-stimulating (FSH) and luteinizing hormone $(\mathrm{LH})$, prolactin $(\mathrm{Prl})$, cortisol $(\mathrm{K})$, testosterone $(\mathrm{T})$, estradiol (E2) on the 5th day of the menstrual cycle and progesterone $(\mathrm{P})$ in serum on the 212 th day of the menstrual cycle. Hormonal studies were carried out using the enzyme-linked immunosorbent assay (ELISA) with "Hema-Medika" LLC (Russia) and "Diagnostic" (USA) kits in accordance with the attached instructions. The medical history was collected in 2 ways: 1 - questionnaire, 2 - information from medical records.

Statistical data processing was carried out using the software package "Statistica-6". The hypothesis on the equality of general means in the 2 compared groups was tested using the non-parametric MannWhitney U-test for independent samples. The difference between the general fractions (frequencies) was estimated using the Student $t$-test. The study of the relationship between quantitative traits was carried out using correlation analysis by the Pearson method.

\section{RESEARCH RESULTS}

Pronounced neuroendocrine disorders were revealed in mothers of the surveyed girls with puberty HS. Among them, obese women predominated -45 $(52,1 \%)(\mathrm{p}<0,05)$, with vegetative disorders -33 $(37,9 \%)(\mathrm{p}<0,05)$, with hyperplastic processes and hormone-dependent tumors of the reproductive system $-20(22,9 \%)(\mathrm{p}<0,05)$. A high percentage of other gynecological diseases was revealed -24 $(27,5 \%)(\mathrm{p}<0,05)$. In addition, $39(44.8 \%)$ mothers had a history of infertility, 18 (20,8\%) - miscarriage. Analysis of the course of pregnancy and childbirth revealed complications in $76(87,5 \%)$ mothers of the subjects in the main group and $15(28,8 \%)$ - in the control one ( $p<0,001) .83,3 \%$ of women in the main group had the perinatal history aggravated by the formation of cerebral disorders $(\mathrm{p}<0,001)$.

The study of the nature of the menstrual function showed that $75(86,4 \%)$ women of the main group had anovulatory menstrual cycles in adolescence $(\mathrm{p}<0,05)$. $37,9 \%$ had dysmenorrhea $(\mathrm{p}<0,05)$ and $25(29,1 \%)$ - premenstrual tension syndrome $(\mathrm{p}<0,05)$. Further analysis of menstrual function showed a difference in the age of onset of menstruation $(\mathrm{p}<0,001)$ (table 1$)$.

In $22(34 \%)$ recorded cases menstruation was not steady yet in the reproductive age $(\mathrm{p}<0,001)$. 
Table 1. The nature of menstrual function in the studied groups

\begin{tabular}{l|l|l|l}
\hline Types of menarche disorders & $\begin{array}{l}\text { Main group } \\
\mathrm{n}=87 \mathrm{M} \pm \mathrm{m}\end{array}$ & $\begin{array}{l}\text { Control } \\
\mathrm{n}=52 \mathrm{M} \pm \mathrm{m}\end{array}$ & $\mathrm{p}$ \\
\hline Menarche age, years & $12,1 \pm 0,8$ & $13,7 \pm 0,7$ & $<0,001$ \\
\hline Cycle establishment time, years & $2,8 \pm 1,6$ & $1,5 \pm 1,1$ & $<0,05$ \\
\hline Duration of menstruation, days & $6,2 \pm 1,8$ & $4,3 \pm 1,7$ & $<0,05$ \\
\hline Duration of cycle, days & $38,9 \pm 2,5$ & $28,4 \pm 2,2$ & $<0,001$ \\
\hline Cycle disorders, abs (\%) & $76(87,3 \%)$ & $13(24,8 \%)$ & $<0,001$ \\
\hline
\end{tabular}

Note: $p$ — significance of differences in relation to the control group

Oligomenorrhea occurred in $58(67 \%)$ patients of the main group, and polymenorrhea - in 20 (23\%) $(\mathrm{p}=0,05, \mathrm{p}=0,03)$. The most common in the main group was a rhythm disorder - in 77,1\% and 67,8\% of women, respectively to subgroups $(p<0,001)$. In addition, in the main group, with a BMI of $<30$ women with hyperpolymeneus prevailed significantly at $73,6 \%$ $(\mathrm{p}<0,001)$, with a BMI $\geq 30-33,3 \%(\mathrm{p}<0,001)$. Acyclic uterine bleeding occurred in 27,5\%, and 36,7\% in both subgroups with HS ( $\mathrm{p}<0,001)$, and algomenorrhea in $37,9 \%(p<0,001)$. In subgroup 1 of patients with HS $(\mathrm{p}<0,05)$ primary amenorrhea was more common. Secondary amenorrhea was registered in both groups almost equally ( $p>0,05)$.

A retrospective analysis of reproductive function revealed that 55 women $(63,2 \%)$ of the main group had spontaneous miscarriages, and in the control group this indicator was 9 patients $(17,3 \%)(\mathrm{p}<0,001)$. In addition, $29(33,3 \%)$ patients in the main group suffered from habitual miscarriage, and a significantly larger percentage of $19(21,8 \%)$ were women in subgroup 2 with a $B M I<30(p<0,05)$. A significant number of patients in the main group with a $\mathrm{BMI} \leq 30$ suffered from primary infertility $(p<0,001)$. Cases of secondary infertility were less common $(8(9,1 \%)$ in the main group and $1(1,9 \%)$ in the control one, $\mathrm{p}<0,05)$.
Against the background of the pathological activation of the hypothalamic-pituitary-ovarian system in subgroup 1 of the main group, increased secretion of $\mathrm{LH}(\mathrm{p}<0,001)$, prolactin $(\mathrm{p}<0,05)$, cortisol $(\mathrm{p}<0,001)$ and testosterone $(\mathrm{p}<0,05)$ was detected, as well as a decrease in FSH $(\mathrm{p}<0,05)$, E2 and progesterone $(\mathrm{p}<0,05)($ table 2$)$.

\section{CONCLUSION}

Research results indicate a decrease in reproductive capacity in $72,4 \%$ of women in the Astrakhan region with the hypothalamic syndrome. Amenorrhea, hyperpolymenorrhea, acyclic uterine bleeding prevailed among the disorders of menstrual function. The structure of reproductive disorders was remarkable for primary infertility and miscarriage with a high frequency.

\section{REFERENCES}

1. ARTymuk N.V. Leptin and the reproductive system of women with hypothalamic syndrome / N.V. Artymuk // Obstetrics and Gynecology. -2003. - № 4. - P. 36-39.

2. Artyukova O.V. Hypothalamic pubertal syndrome/ O.V. Artyukova, V.F. Kokolina // Bulletin of Russian assoc. of obstetricians and gynecologists. - 1997. - № 2. - P. 45-48.

3. WAYNE A.M. Hypothalamic syndrome / A.M. Wayne, T. Voznesenskaya // Doctor.- 2000. -№4. P. 12-14.

4. Kulakov V.I., Prilepskaya V.N., Radzinsky V.E. Guide to outpatient care in obstetrics and gynecology - Moscow: GEOTAR-Media, 2007. - P. 424-435.

5. Suturina L.V. The main pathogenetic mechanisms and methods for the correction of reproductive disorders in patients with hypothalamic syndromes / L.V. Suturina, L.I. Kolesnikova. - Novosibirsk: Science, 2001. - p. 132.

6. Uvarova, E.V. Modern problems of reproductive health of girls / E. V. Uvarova, V. I. Kulakov // Reproductive health of adolescent girls. 2005. - № 1. - P. 6-10.

Table 2. Indicators of the hormonal status of the surveyed women

\begin{tabular}{l|l|l|l|l|l}
\hline Indicators $\mathrm{M} \pm \mathrm{m}$ & $\begin{array}{l}\mathrm{BMI} \geq 30 \text { subgroup } 1, \\
\mathrm{n}=45\end{array}$ & $\begin{array}{l}\mathrm{BMI} \leq 30, \text { Subgroup } \\
2, \mathrm{n}=43\end{array}$ & Control, $\mathrm{n}=52$ & $\mathrm{P}_{2}$ (1-Control) & $\mathrm{P}_{3}$ (2-Control) \\
\hline $\mathrm{FSH}, \mathrm{mme} / \mathrm{I}$ & $4,2 \pm 1,7^{*}$ & $8,3 \pm 1,8$ & $6,6 \pm 1,7$ & $\mathrm{p}<0,01$ & $\mathrm{p}<0,05$ \\
\hline $\mathrm{LH}, \mathrm{mme} / \mathrm{I}$ & $14,3 \pm 2,4^{*}$ & $7,7 \pm 2,6$ & $6,4 \pm 2,2$ & $\mathrm{p}<0,002$ & $\mathrm{p}<0,05$ \\
\hline $\mathrm{Prl}, \mathrm{mme} / \mathrm{I}$ & $558,2 \pm 29,2^{*}$ & $358,2 \pm 28,7$ & $197,1 \pm 25,1$ & $\mathrm{p}<0,05$ & $\mathrm{p}<0,001$ \\
\hline $\mathrm{E}, \mathrm{pg} / \mathrm{ml}$ & $67,7 \pm 19,4^{*}$ & $54,8 \pm 23,8$ & $48,5 \pm 22,3$ & $\mathrm{p}<0,05$ & $\mathrm{p}<0,05$ \\
\hline $\mathrm{P}, \mathrm{nmol} / \mathrm{I}$ & $13,6 \pm 3,4^{* *}$ & $29,2 \pm 23,8$ & $57,8 \pm 4,4$ & $\mathrm{p}<0,001$ & $\mathrm{p}<0,05$ \\
\hline $\mathrm{K}, \mathrm{nmol} / \mathrm{I}$ & $224,2 \pm 21,8^{* *}$ & $427,4 \pm 26,6$ & $127,3 \pm 25,4$ & $\mathrm{p}<0,05$ & $\mathrm{p}<0,001$ \\
\hline $\mathrm{T}, \mathrm{nmol} / \mathrm{I}$ & $1,3 \pm 0,6^{*}$ & $1,9 \pm 0,9$ & $0,8 \pm 0,7$ & $\mathrm{p}<0,05$ & $\mathrm{p}<0,05$ \\
\hline
\end{tabular}

The significance of differences ${ }^{*} p_{1}<0,05,{ }^{* *} p_{1}<0,001$ - relative to subgroup 2. $p_{2} p_{3}$ - relative to the control group 